\title{
Inflammatory response and bone healing capacity of two porous calcium phosphate ceramics in critical size cortical bone defects
}

Citation for published version (APA):

Chatterjea, A., van der Stok, J., Danoux, C. B., Yuan, H., Habibovic, P., van Blitterswijk, C. A., Weinans, H., \& de Boer, J. (2014). Inflammatory response and bone healing capacity of two porous calcium phosphate ceramics in critical size cortical bone defects. Journal of Biomedical Materials Research Part A, 102(5), 1399-1407. https://doi.org/10.1002/jbm.a.34815

Document status and date:

Published: 01/05/2014

DOI:

10.1002/jbm.a.34815

Document Version:

Publisher's PDF, also known as Version of record

\section{Document license:}

Taverne

Please check the document version of this publication:

- A submitted manuscript is the version of the article upon submission and before peer-review. There can be important differences between the submitted version and the official published version of record.

People interested in the research are advised to contact the author for the final version of the publication, or visit the DOI to the publisher's website.

- The final author version and the galley proof are versions of the publication after peer review.

- The final published version features the final layout of the paper including the volume, issue and page numbers.

Link to publication

\footnotetext{
General rights rights.

- You may freely distribute the URL identifying the publication in the public portal. please follow below link for the End User Agreement:

www.umlib.nl/taverne-license

Take down policy

If you believe that this document breaches copyright please contact us at:

repository@maastrichtuniversity.nl

providing details and we will investigate your claim.
}

Copyright and moral rights for the publications made accessible in the public portal are retained by the authors and/or other copyright owners and it is a condition of accessing publications that users recognise and abide by the legal requirements associated with these

- Users may download and print one copy of any publication from the public portal for the purpose of private study or research.

- You may not further distribute the material or use it for any profit-making activity or commercial gain

If the publication is distributed under the terms of Article $25 \mathrm{fa}$ of the Dutch Copyright Act, indicated by the "Taverne" license above, 


\section{Always Be Ready for What's Next with Patient Safety Net"}

Multiple studies over 10 years at Dartmouth-Hitchcock Medical Center have shown improved clinical outcomes and reduced cost of care.

\section{0}

preventable deaths or brain damage due to opioid-induced respiratory depression in monitored patients over 10 years

\section{$\downarrow 50 \%$}

approximate reduction in ICU transfers ${ }^{2}$

\section{$\downarrow 60 \%$}

approximate reduction in rapid response team activations

\section{$\downarrow 7$ Million}

Masimo SET is used to monitor over 200 million patients a year."

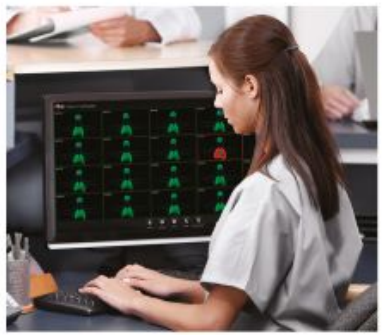

$>$ Masimo $\mathrm{SET}^{s}$ has been shown in more than 100 independent and objective studies to outperform other pulse oximetry technologies ${ }^{5}$

$>$ Radius PPG ${ }^{\text {Th }}$ tetherless pulse oximetry allows you to monitor patients from outside the room and beyond

$>$ Remote patient monitoring at central view stations

$>$ Real-time data and alarm notifications on clinicians' smartphones with Replica ${ }^{\mathrm{T}}$ 


\title{
Inflammatory response and bone healing capacity of two porous calcium phosphate ceramics in critical size cortical bone defects
}

\author{
Anindita Chatterjea, ${ }^{1 *}$ Johan van der Stok ${ }^{2 *}$ Charlène B. Danoux, ${ }^{1}$ Huipin Yuan, ${ }^{1}$ \\ Pamela Habibovic, ${ }^{1}$ Clemens A. van Blitterswijk, ${ }^{1}$ Harrie Weinans, ${ }^{2,3,4}$ Jan de Boer ${ }^{1}$ \\ ${ }^{1}$ Department of Tissue Regeneration, MIRA Institute for Biomedical Technology and Technical Medicine, University of \\ Twente, Enschede, the Netherlands \\ ${ }^{2}$ Department of Orthopaedics, Orthopaedic Research Laboratory, Erasmus University Rotterdam Medical Center, Rotterdam, \\ the Netherlands \\ ${ }^{3}$ Department of Orthopaedics \& Department of Rheumatology, University Medical Centre Utrecht, Utrecht, The Netherlands \\ ${ }^{4}$ Department of Biomechanical Engineering, Delft Technical University, Delft, The Netherlands
}

Received 7 January 2013; revised 7 May 2013; accepted 20 May 2013

Published online 12 June 2013 in Wiley Online Library (wileyonlinelibrary.com). DOI: 10.1002/jbm.a.34815

\begin{abstract}
In the present study, two open porous calcium phosphate ceramics, $\beta$-tricalcium phosphate ( $\beta$-TCP), and hydroxyapatite (HA) were compared in a critical-sized femoral defect in rats. Previous comparisons of these two ceramics showed significantly greater osteoinductive potential of $\beta$ TCP upon intramuscular implantation and a better performance in a spinal fusion model in dogs. Results of the current study also showed significantly more bone formation in defects grafted with $\beta$-TCP compared to HA; however, both the ceramics were not capable of increasing bone formation to such extend that it bridges the defect. Furthermore, a more pronounced degradation of $\beta$-TCP was observed as compared to HA. Progression of inflammation and initiation of new bone formation were assessed for both materials at multiple time points by histological and fluorochrome-based
\end{abstract}

analyses. Until 12 days postimplantation, a strong inflammatory response in absence of new bone formation was observed in both ceramics, without obvious differences between the two materials. Four weeks postimplantation, signs of new bone formation were found in both $\beta$-TCP and HA. At 6 weeks, inflammation had subsided in both ceramics while bone deposition continued. In conclusion, the two ceramics differed in the amount of bone formed after 8 weeks of implantation, whereas no differences were found in the duration of the inflammatory phase after implantation or initiation of new bone formation. $\odot 2013$ Wiley Periodicals, Inc. J Biomed Mater Res Part A: 102A: 1399-1407, 2014.

Key Words: hydroxyapatite, tricalcium phosphate, osteoinductive potential, rat femoral defect, inflammatory response

How to cite this article: Chatterjea A, van der Stok J, Danoux CB, Yuan H, Habibovic P, van Blitterswijk CA, Weinans $H$, de Boer J. 2014. Inflammatory response and bone healing capacity of two porous calcium phosphate ceramics in critical size cortical bone defects. J Biomed Mater Res Part A 2014:102A:1399-1407.

\section{INTRODUCTION}

Autologous bone is currently the gold standard for grafting bone defects. However, the limited availability and postoperative complications associated with the harvesting procedure site have necessitated the search for bone graft substitutes. ${ }^{1}$ Substitute materials, such as calcium phosphate (CaP) ceramics, have been used in a widespread of trauma and orthopedic related indications. ${ }^{2,3,5}$ The interest in CaP ceramics can be attributed to their chemical resemblance with bone mineral and their osteoconductivity. ${ }^{4}$ However, unless additionally endowed with a osteoinductive stimulus, the general performance of CaP ceramics remains inferior to autologous bone.

Osteoinductivity is the ability of a material to induce differentiation of progenitor cells into the osteogenic lineage to form active osteoblasts. ${ }^{15}$ Differentiation into active osteoblasts is induced through secretion of osteoinductive factors such as bone morphogenetic proteins. Addition of osteoinductive factors was therefore thought to be essential to enhance the performance of CaP ceramics. More recently, it was found that some open porous CaP ceramics could induce bone formation in the absence of any osteoinductive factors, making these $\mathrm{CaP}$ ceramics potentially suitable as off-the-shelf alternatives to autologous bone grafts. ${ }^{6-9}$

The osteoinductive performance of open porous CaP ceramics, however, varies strongly and is influenced by chemical composition and structure (e.g., macroporosity, microporosity, surface concavities, surface area, and roughness), as recently reviewed. ${ }^{10}$ Four different CaP ceramics

*These authors contributed equally to this work.

Correspondence to: J. de Boer; e-mail: j.deboer@utwente.nl

Contract grant sponsor: TeRM Smart Mix Program of the Netherlands Ministry of Economic Affairs and the Netherlands Ministry of Education, Culture, and Science 
were developed and tested in vivo by our group. ${ }^{16}$ Open porous $\mathrm{CaP}$ ceramic particles (1-2 $\mathrm{mm}$ ) tested were $\beta$ tricalcium phosphate ( $\beta$-TCP) ceramic with a specific surface area of $1.2 \mathrm{~m}^{2} / \mathrm{g}$, phase-pure hydroxyapatite (HA) ceramic with specific surface area of $0.1 \mathrm{~m}^{2} / \mathrm{g}$ and two biphasic ceramics both consisting of HA and $\beta$-TCP in a weight ratio $80: 20$, but sintered at different temperatures to vary microstructural properties and specific surface area (1 vs $0.2 \mathrm{~m}^{2} /$ g). Twelve weeks after implantation in canine paraspinal muscles (1 $\mathrm{mL}$ of ceramic particles) and spinal fusion regions $(5 \mathrm{~mL}$ of ceramic particles), the largest difference was found between $\beta$-TCP and HA. $\beta$-TCP gave five times more bone in both paraspinal muscles (0 vs 20\% area of available pore space covered with bone) and spinal fusion regions (5 vs $25 \%$ area of available pore space covered with bone).

Implantation at ectopic sites (e.g. intramuscular or subcutaneous) is an established method to screen materials osteoinductive properties since seminal work by Urist ${ }^{11}$ in the 1960s. However, extrapolating this data to clinically relevant bone defects requires evaluation in clinically more relevant models. As bone is not naturally present at the site of bone formation in spinal fusion models, this model cannot be considered fully orthotopic and it remains to be further elucidated whether the osteoinductive performance of $\beta$ TCP is relevant in critical-sized orthotopic bone defects. Furthermore, the osteoinductive performance of $\beta$-TCP may be the effect of faster degradation and release of microparticles altering the intrinsic inflammatory phase reaction before bone formation. ${ }^{12-14}$ Others have shown that bone formation benefits from a mild contained inflammatory reaction, and strong inflammatory reactions can make the environment hostile, and hamper bone formation. ${ }^{20}$

The aim of the current study was to determine whether the osteoinductive performance of $\beta$-TCP is relevant to bone formation in a critical-sized cortical bone defect in rats, compared to the less osteoinductive HA. Furthermore, we aimed to determine the duration of the inflammatory response within this bone defect model after implantation of $\beta$-TCP and HA, to assess whether the duration of the inflammatory response could be related to bone formation.

\section{MATERIALS AND METHODS}

\section{Synthesis and characterization of HA and $\beta$-TCP ceramics}

In this study two CaP ceramics were investigated: HA and $\beta$-TCP. The HA ceramic was prepared from HA powder (Merck) using the dual phase mixing method ${ }^{20}$ consisting of three steps. First, HA slurry was prepared by mixing $2 / 3 \mathrm{wt}$ $\%$ of calcined HA powder with $1 / 3$ wt \% water containing deflocculant (dolpix CE 64, Germany) and binder (carboxylmethyl cellulose; Pomosin BC, the Netherlands). Then, two immiscible phases were mixed: water-based HA slurry and polymethylmethacrylate (PMMA) resin with a volume ratio of 1:1. The PMMA resin consisted of PMMA powder, methylmethacrylate (MMA) monomer, and naphthalene $(<10 \%$, v/ v) as an additional fugitive pore maker. Finally, the mixture was polymerized, dried and pyrolized and sintered at $1250^{\circ} \mathrm{C}$ for $8 \mathrm{~h}$. The $\beta$-TCP ceramic was fabricated by the $\mathrm{H}_{2} \mathrm{O}_{2}$ method as described previously ${ }^{21}$ using $\beta$-TCP powder purchased from Plasma Biotal (Derbyshire, UK). The powder was mixed with $2 \% \mathrm{H}_{2} \mathrm{O}_{2}$ solution $(1.0 \mathrm{~g}$ powder/1.20 \pm $0.05 \mathrm{~mL}$ solution) and naphthalene particles (710-1400 $\mu \mathrm{m}$; 100 g powder/30 g; Fluka Chemie, Zwijndrecht, the Netherlands) at $60^{\circ} \mathrm{C}$. The naphthalene was then evaporated at $80^{\circ} \mathrm{C}$ and the porous bodies were dried, and sintered at $1100^{\circ} \mathrm{C}$ for $8 \mathrm{~h}$. For both $\mathrm{CaP}$ ceramics, a lathe was used to produce the cylinders. Subsequently, the cylinders were cut into implants $6 \mathrm{~mm}$ in length and $3 \mathrm{~mm}$ in diameter. Implants were cleaned ultrasonically with acetone, 70\% ethanol and demineralized water, dried at $80^{\circ} \mathrm{C}$, and sterilized by gamma irradiation before implantation.

The chemical composition and the crystallinity of the ceramics were analyzed using X-ray diffraction (Miniflex, Rigaku, Japan). The macropore size and porosity of the CaP ceramics were determined by image analysis on thin sections using a KS400 image system (Carl Zeiss, Germany) attached to a light microscope (LM, objective, $\times 10$; Nikon, Japan). Thin sections were made on a Leica diamond saw after embedding CaP ceramics blocks in MMA. The microstructure was evaluated as described previously using a scanning electron microscope (XL30, Environmental SEMField Emission Gun, Philips). Specific surface area of the two ceramics was analyzed by mercury intrusion (Micromeritics Instrument).

\section{Animal experiment}

In total, 34 skeletally mature 18-week-old male Wistar rats were used on approval by the institution's Animal Ethics Committee (EUR2317). Animals were housed according to national guidelines for the care and use of laboratory animals. A 6-mm femoral bone defect was grafted with either HA $(n=14), \beta$-TCP $(n=14)$, or left empty $(n=6)$.

The surgical procedures were performed aseptically on a heated plate under general anesthesia (isoflurane $1-3.5 \%$ in air). Before surgery, the rats received a subcutaneous injection of buprenorphine $0.3 \mathrm{mg} / \mathrm{mL}$ Temgesic; Schering-Plough B.V., Amstelveen, the Netherlands) at a dose of $0.05 \mathrm{mg} / \mathrm{kg}$ body weight and enrofloxacine $(25 \mathrm{mg} / \mathrm{mL}$ Baytril; Bayer B.V., Mijdrecht, the Netherlands) at a dose of $5 \mathrm{mg} / \mathrm{kg}$ body weight. The right thigh was shaved and disinfected with polydine tincture. Then, the femur shaft was exposed by a longitudinal skin incision, and blunt dissection of the underlying fascia between the vastus lateralis muscle and the biceps femoris muscle. Next, a $23 \mathrm{~mm}$ PEEK plate (RatFix Plate, RISystem; AO Foundation, Davos, Switzerland) was fixated onto the anterolateral side of the femur by three cortical and three distal screws $(6.5 \mathrm{~mm} \times 0.8 \mathrm{~mm} \emptyset$ ShoulderScrews, RISystem; AO Foundation). Two osteotomies were performed using a saw guide with a wire saw (Drill\&Saw guide, RISystem; AO Foundation) to remove a $6 \mathrm{~mm}$ large bone segment. The resulting defect was then grafted with one of the implants or left empty (Fig. 1). The wound was irrigated with sterile saline and sutured with 5-0 Vicryl sutures. Postoperative care consisted of subcuteaneous administration of 
A

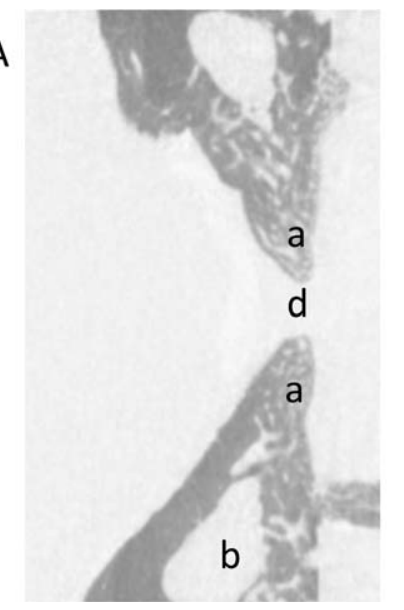

B

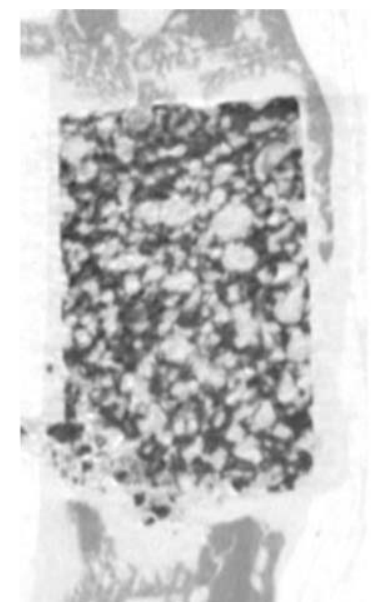

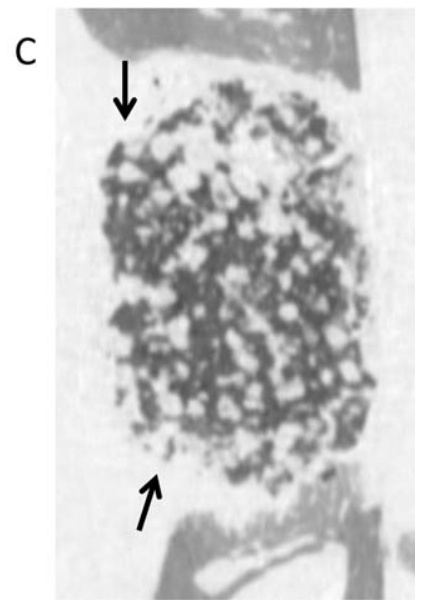

FIGURE 1. Overview of the rat femoral defect after 8 weeks by micro-CT. Micro-CT evaluation after 8 weeks of implantation showed (A) absence of complete bridging of the empty defect confirming its critical size (a, two ends of the bone; b, marrow cavity; and d, the actual defect), (B) maintenance of the shape of the HA implant, and (C) rounding of the edges of the $\beta$-TCP implant, suggestive of the more pronounced degradation of $\beta$-TCP as compared to HA. The two ends of the bone (a); marrow cavity (b); and the actual defect (d).

buprenorphine $(0.3 \mathrm{mg} / \mathrm{mL}$ Temgesic, $0.05 \mathrm{mg} / \mathrm{kg}$ body weight) as analgesia twice a day for the first 3 days.

To visualize the dynamics of bone growth, rats received sequential subcutaneous injections with fluorochrome labels at 4 weeks [12.5 mg/mL calcein green (CG), $10 \mathrm{mg} / \mathrm{kg}$ body weight; Sigma Aldrich, Zwijndrecht, the Netherlands] and 6 weeks [50 mg/mL xylenol orange (XO), $100 \mathrm{mg} / \mathrm{kg}$ body weight, Sigma Aldrich].

To qualitatively assess the duration of the inflammatory response, two animals from the HA and the $\beta$-TCP group were sacrificed after 5 and 12 days, whereas one animal from of each group was sacrificed after 6 weeks. To quantify bone formation, the remaining nine animals in the groups that received either HA or $\beta$-TCP were scarified after 8 weeks. Another six animals in whom the defect was left empty were included to confirm the critical size of the defect.

\section{Microcomputed tomography evaluation}

Microcomputed tomography (micro-CT) scans were acquired to provide a qualitative overview of bone integration and resorption of the CaP ceramics and to confirm the critical size of the defect. Right femurs were collected, fixated in formalin (Merck chemicals; the Netherlands) and kept hydrated during the scanning process by wrapping them in foil. A SkyScan 1076 micro-CT scanner (Bruker micro-CT N.V., Kontich, Belgium) was used with an $18 \mu \mathrm{m}$ resolution protocol (70 kV energy, $100 \mu \mathrm{A}$ current, $1.0 \mathrm{~mm}$ $\mathrm{Al} / 0.25 \mathrm{~mm} \mathrm{Cu}$ filter). CT images were converted into three-dimensional reconstructions of cross-sectional images using volumetric reconstruction software NRecon version 1.5 (Bruker micro-CT N.V.).

\section{Histology and histomorphometry}

After micro-CT scanning, fixated samples were kept overnight, dehydrated within an industrial microwave using JFC solution (Leica Microsystems, Rijswijk, the Netherlands) and transferred into MMA solution (L.T.I., Bilthoven, the Netherlands) and polymerized at $37^{\circ} \mathrm{C}$ within 3 days. Sections were made at every level of the sample with an approximate thickness of 10-15 $\mu \mathrm{m}$ using a modified interlocked diamond saw (Leica Microtome, Nussloch, Germany). Sections were either stained with $1 \%$ methylene blue (Sigma) and $0.3 \%$ basic fuchsin (Sigma) after etching with an $\mathrm{HCl}$ / ethanol mixture for routine histology and histomorphometry or left unstained for epifluorescence microscopy with a LM (E600, Nikon) equipped with a quadruple filter block (XF57, dichroic mirror 400, 485, 558, and $640 \mathrm{~nm}$; Omega Filters, Didam, the Netherlands).

Histological sections were qualitatively analyzed by light microscopy (Leica), and each section was scored either positive or negative for bone formation. For quantitative histomorphometry, high-resolution digital photographs were made from three randomly selected sections from each sample. Bone and $\mathrm{CaP}$ ceramic were manually pseudocolored green and red, respectively, using Photoshop CS2 (Adobe Systems). A custom-made Matlab script was used to measure the percentage of bone in the available pore area in the total region of implant as well as in the central area of the implant. The central area was defined as the area covered by a rectangle drawn along the points $1 \mathrm{~mm}$ on either side of the horizontal line running through the center of the implant and $2 \mathrm{~mm}$ on either side of the vertical line running through the center of the implant (Fig. 5). For statistical analysis, a two sided paired Student's $t$-test was used to analyze differences between $\beta$-TCP and HA.

\section{RESULTS}

\section{Characterization of HA and $\beta$-TCP ceramics}

HA and $\beta$-TCP ceramics similar to those used in our previous study were produced. ${ }^{16}$ Chemical and structural characteristics of the two ceramics are presented in Table I.

\section{Micro-CT evaluation}

Micro-CT scans showed that none of the six empty defects (control group) show bridging within the 8 weeks implantation period, thereby confirming the critical size of thedefect 
TABLE I. Characterization of the Calcium Phosphate Ceramics In Vitro

\begin{tabular}{lll}
\hline & HA & \\
& HA & $\begin{array}{l}\beta \text {-TCP } \\
90 \% \beta-\text { TCP } \\
\text { and }<10 \% \mathrm{HA}\end{array}$ \\
$\begin{array}{lll}\text { Sintering } \\
\quad \text { Temperatures }\end{array}$ & $1250{ }^{\circ} \mathrm{C}$ & $1050{ }^{\circ} \mathrm{C}$ \\
$\begin{array}{l}\text { Macroporosity } \\
\text { Microporosity }\end{array}$ & $\pm 60 \%$ & $\pm 60 \%$ \\
Surface area & Low $( \pm 5 \%)$ & High $( \pm 15 \%)$ \\
\hline
\end{tabular}

aVolume percentage of micropores smaller than $10 \mu \mathrm{m}$ within the ceramic.

[Fig. 1(A)]. Micro-CT scans of defects grafted with HA and $\beta$-TCP some limited bone formation originating from the proximal and distal host bone and areas of direct boneimplant contact were limited. Differences in resorption between HA and $\beta$-TCP were noted in the defects grafted with the two ceramics. Whereas HA retained its cylindrical shape [Fig. 1(B)], $\beta$-TCP clearly showed signs of degradation in the regions closest to the host bone bed [Fig. 1(C)].

\section{Histology and histomorphometry}

In line with the micro-CT scan findings, histology of the empty defects confirmed the critical size of the defect. The defect site was filled with loosely organized fibrous tissue, and no bridging of the defect occurred [Fig. 2(A)]. Rounding of the edges and loss of structure were observed in the $\beta$-TCP after 8 weeks [Fig. 2(B)], in contrast to HA implants that retained the original shape [Fig. 2(C)]. Direct contact between HA or $\beta$-TCP and the proximal and distal femoral bone was limited, fibrous tissue had formed at the majority of the interface.

Initiation and progression of inflammation for HA and $\beta$-TCP was determined by histology after 5 and 12 days and

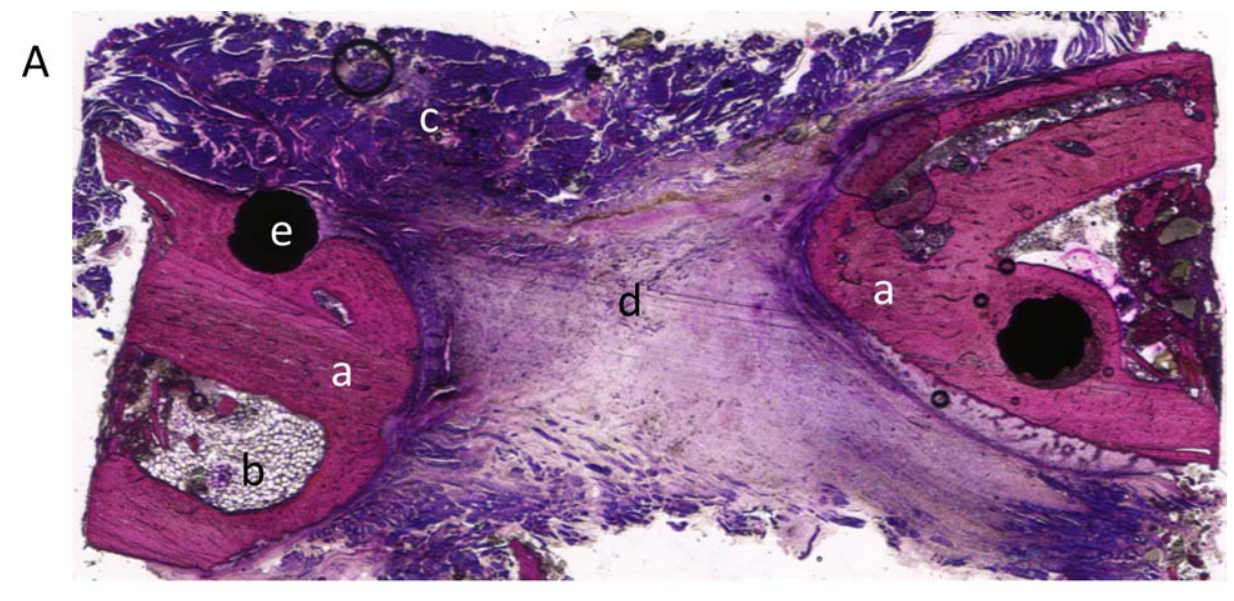

B

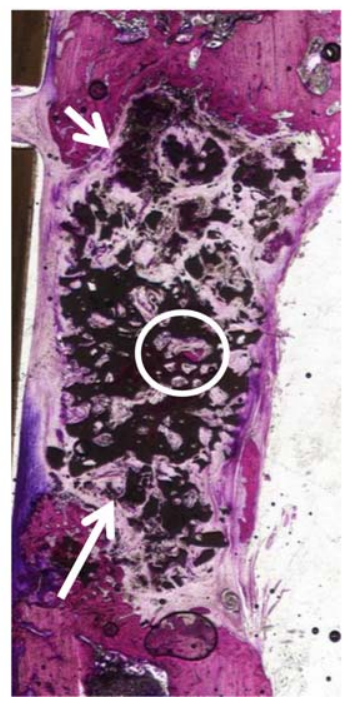

C

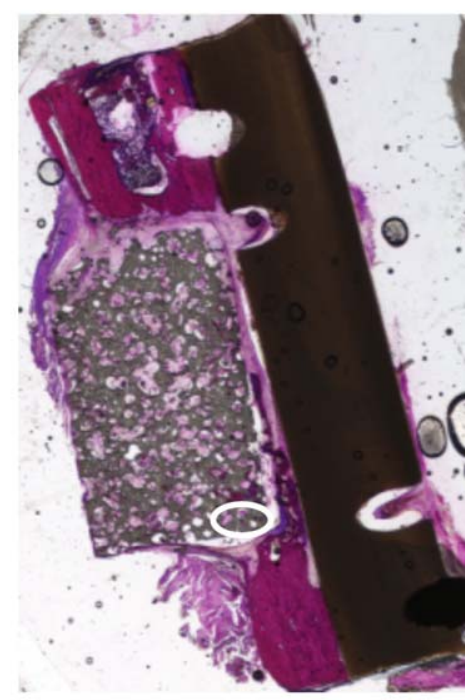

FIGURE 2. Overview of the rat femoral defect after 8 weeks by histology. Histology findings at 8 weeks were very similar to the micro-CT scan findings. At 8 weeks, (A) incomplete bridging of the empty defect with presence of poorly organized fibrous tissue between the two cut ends of the femur confirmed the critical size of the defect, (B) presence of rounded edges in the $\beta$-TCP (marked by white arrows), suggested a pronounced degradation at these sites, and (C) maintenance of the cylindrical shape of the HA ceramic suggested limited degradation. Islands of bone were seen in all the $\beta$-TCP and some HA ceramics (encircled areas). The two ends of the bone (a); marrow cavity (b); muscle surrounding the bone and defect site (c); the actual defect (d); and screws used to hold the PEEK plate in place over the defect (e). [Color figure can be viewed in the online issue, which is available at wileyonlinelibrary.com.] 
A
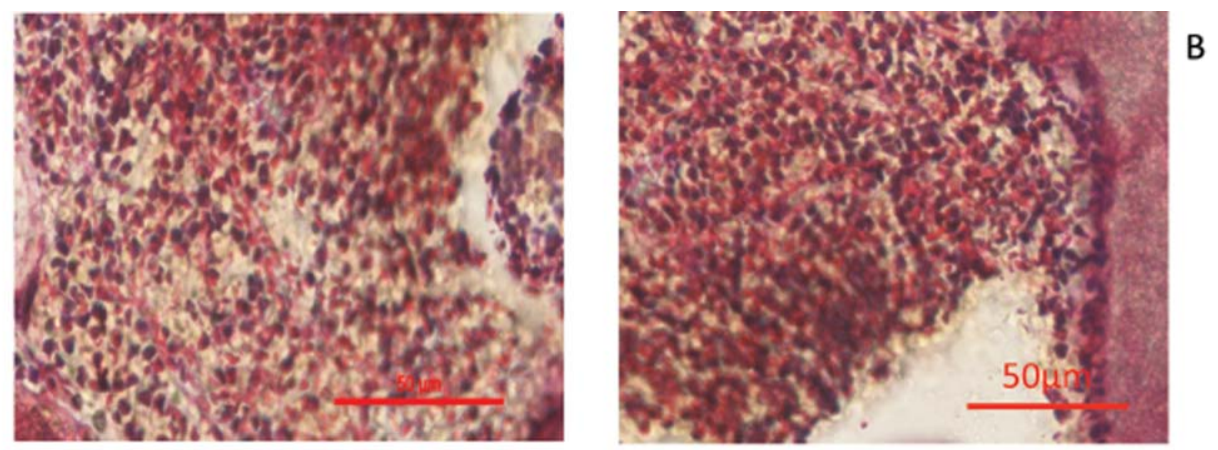

C
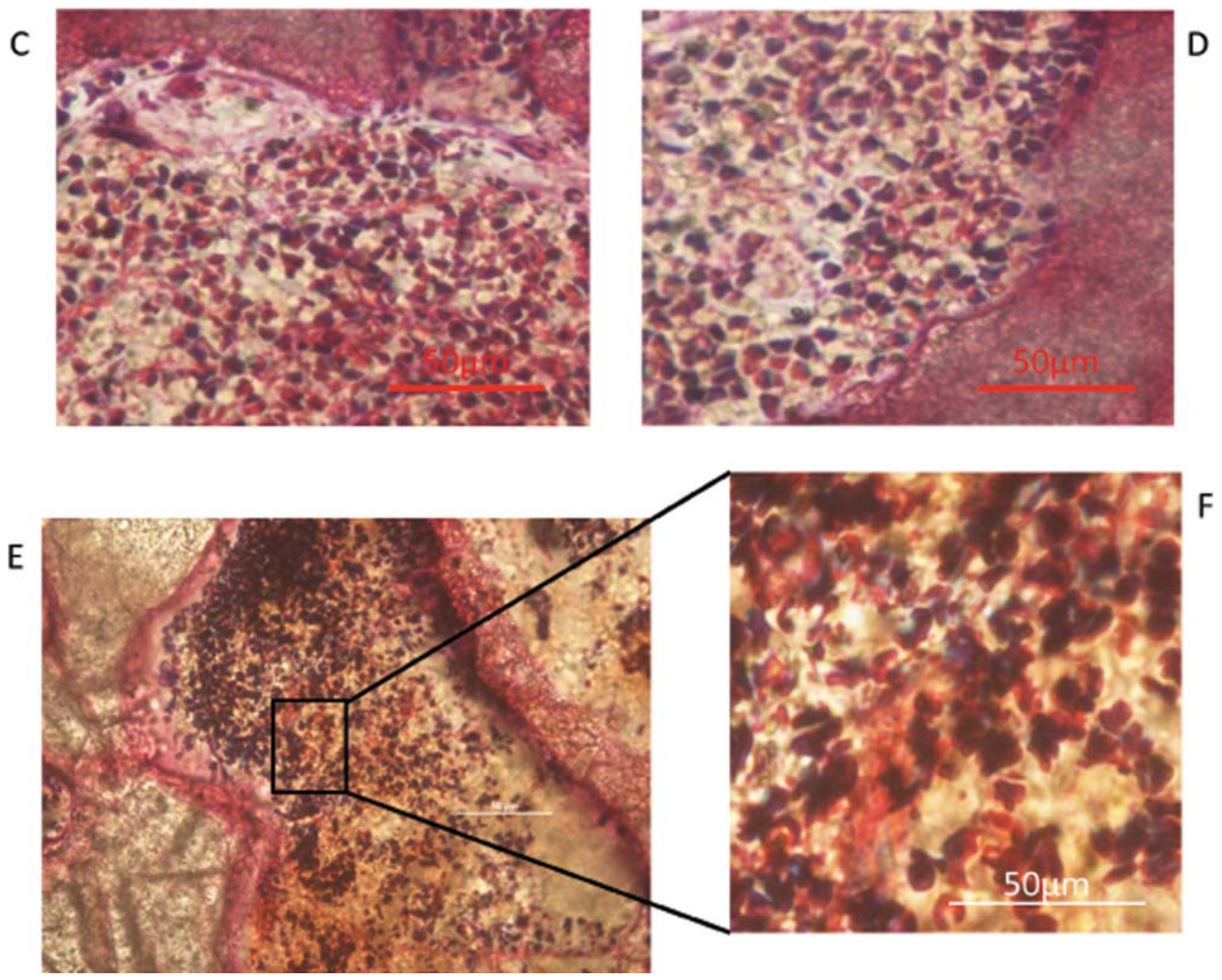

FIGURE 3. Histological overview of the $\beta$-TCP and HA ceramics after 5 and 12 days. Rounded cells, probably of inflammatory origin within the pores of the $\beta$-TCP and HA ceramics after 5 days (A and B, respectively) and after 12 days (C and D, respectively). A $40 \times$ magnified view of the inflammatory cells in the $\beta$-TCP ceramic after 12 days $(E)$ and an enlargement of the black square area (F). [Color figure can be viewed in the online issue, which is available at wileyonlinelibrary.com.]

6 and 8 weeks. Clusters of round cells, highly suggestive of inflammatory cells such as monocytes or lymphocytes were found within the pores of both the HA and the $\beta$-TCP implants at 5 and 12 days [Fig. 3(A-F)]. No obvious difference was observed between the two ceramics. These cells were not seen in either ceramic after 6 weeks. Instead, small islands of new bone formation were observed in the pores of both HA [Fig. 4(A,B)] and $\beta$-TCP [Fig. 4(C,D)]. These results suggested that the cellular infiltration which was probably of inflammatory origin subsided between 12 days and 6 weeks of implantation, whereas the bone formation was initiated during this time.

The amount of bone increased between 6 and 8 weeks for both HA and $\beta$-TCP. The insets in Figure 4(E,F) demonstrate the mineralized matrix, bone lining cells and embedded osteocytes which histologically characterize bone. New bone formation was observed in all $\beta$-TCP implants (9/9) and in seven HA implants (7/9). Total amount of bone formed in defects grafted with $\beta$-TCP ceramic was significantly more than that formed in defects grafted with HA $(3.6 \pm 2.1 \%$ vs $1.4 \pm 1.6 \%$, respectively, of the available pore area was filled with newly formed bone; Fig. 5(A)]. However, no significant difference was found in the amount of bone that formed in the central area of the $\beta$-TCP or HA implants, where chances of bone ingrowth from the host bone bed were lowest. Although $3.1 \pm 2.5 \%$ of the available pore area in the central part of the defect was filled with newly formed bone in $\beta$-TCP, the corresponding value for HA was $2.5 \pm 2.4 \%$ [Fig. 5(B)].

Analysis of the fluorochrome markers showed that both CG and XO label were found in areas adjacent to host bone 

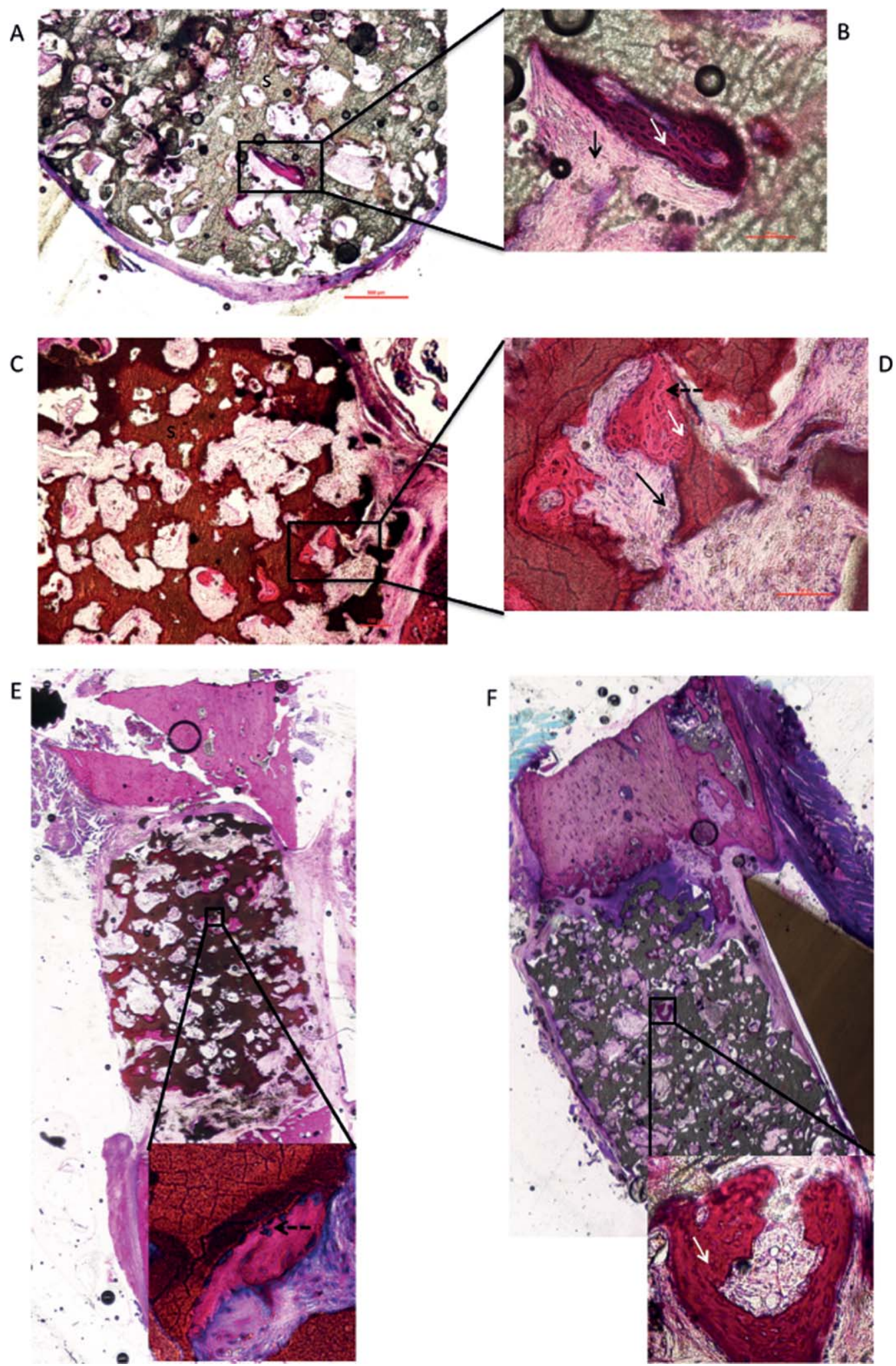

FIGURE 4. Histological overview of $\beta$-TCP and HA ceramics after 6 and 8 weeks. Absence of the inflammatory cells with concomitant presence of small islands of new bone within the HA (A) and $\beta$-TCP (C) ceramics after 6 weeks. Magnified view of bone formed within the pores of the HA (B) and $\beta$-TCP implants (D). Note the presence of osteocytes (white arrows) embedded in the pink matrix and the bone lining cells (dotted black arrows). The rest of the pore was filled by cells with elongated nuclei (fibrous tissue marked by black arrows). After 8 weeks, again islands of new bone were observed in both $\beta-\mathrm{TCP}(\mathrm{E})$ and HA (F). The inset images show magnified views of the newly formed bone. Note the presence of osteocytes, bone lining cells, and matrix. [Color figure can be viewed in the online issue, which is available at wileyonlinelibrary.com.] 

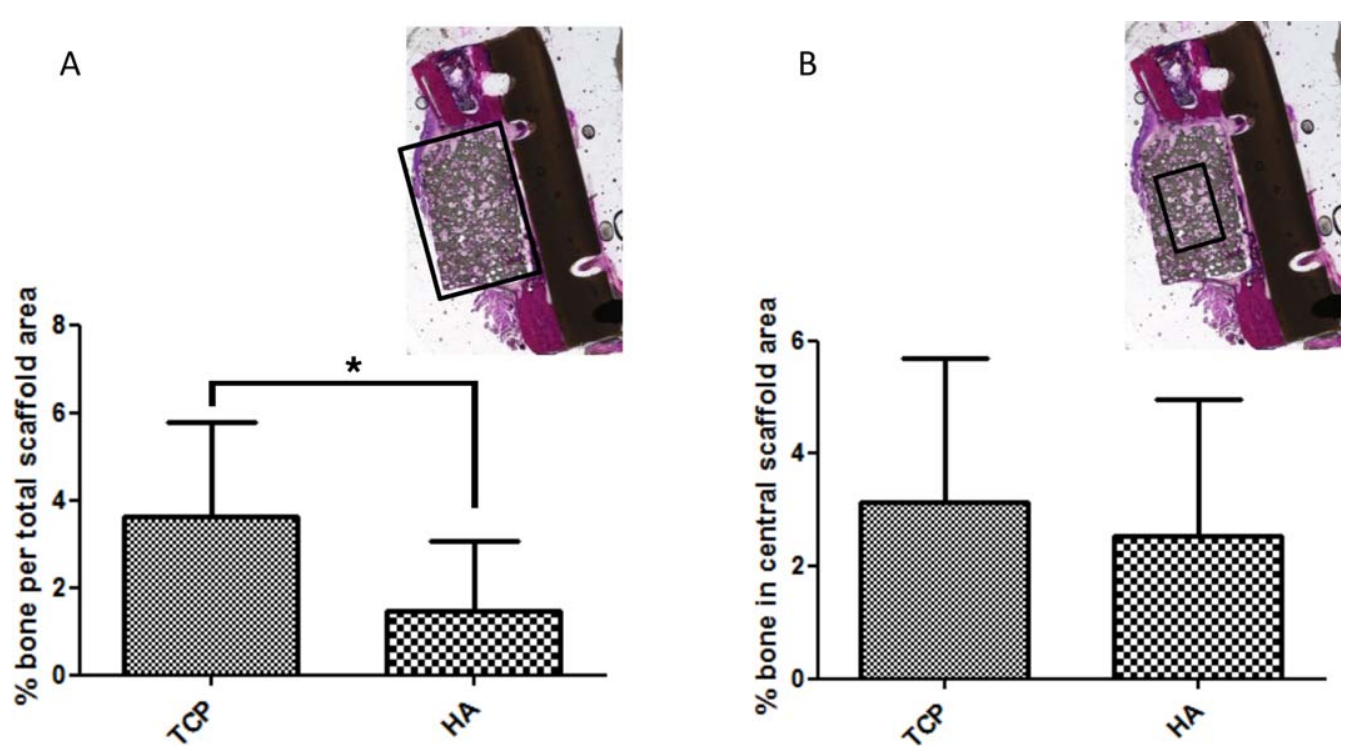

FIGURE 5. Quantification of bone formed within the pores of HA and $\beta$-TCP cylinders. The amount of bone formed was determined in the available pore area of the total implant (A) and in the center of the implant (B). The black rectangle in both the insets represents the area of the implant in which the new bone deposition was calculated. The error bars represent the standard deviation. Statistical analysis using the Student's paired $t$ test. ${ }^{*} p<0.05$. [Color figure can be viewed in the online issue, which is available at wileyonlinelibrary.com.]

bed, as well as in the central area of the defect [denoted by the rectangle in Fig. 5(B)], suggesting early bone deposition throughout the implanted ceramics. Presence of CG label in the two ceramics indicated that bone formation had started in both HA and $\beta$-TCP earlier than 4 weeks postimplantation [Fig. 6(A,B)]. Continued deposition and remodeling of bone
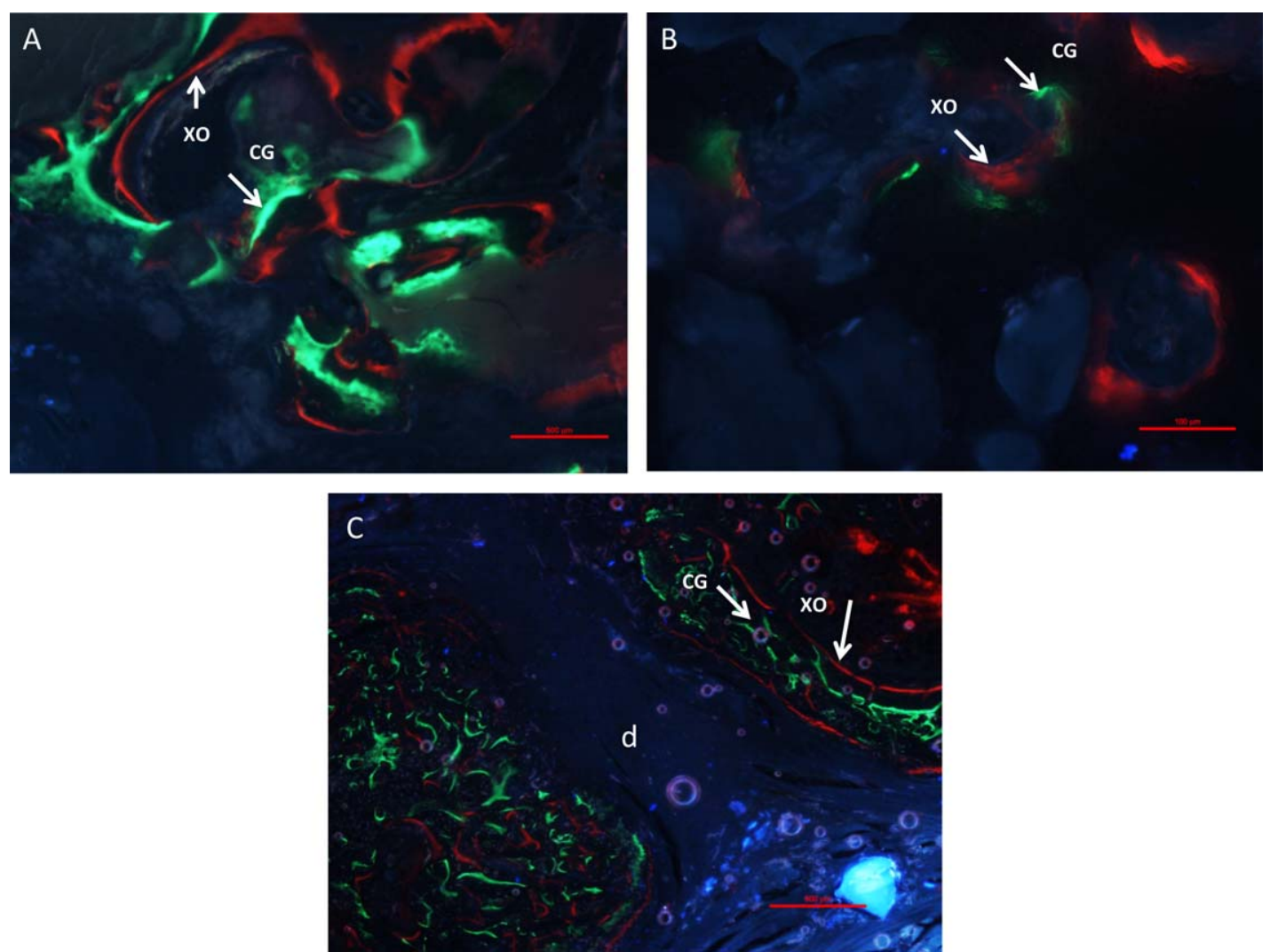

FIGURE 6. Dynamics of bone deposition within the two ceramics. Fluorescence microscopy images (original magnification $\times 10$ ) of the fluorochrome markers in the center of the $\beta$-TCP $(A)$ and HA $(B)$ ceramics. $C$ represents a $\times 4$ time magnified image of the two ends of the femur with the intervening defect (d). CG, calcein green; XO, xylenol orange; SC, ceramic scaffold. [Color figure can be viewed in the online issue, which is available at wileyonlinelibrary.com.] 
at 8 weeks in the two $\mathrm{CaP}$ ceramics was suggested by the presence of the XO label. In the empty defect, fluorochrome markers were only observed at the two ends of the defect, close to the host bone bed, indicating bone deposition and remodeling as a part of the body's intrinsic healing process [Fig. 6(C)].

\section{DISCUSSION}

The present study aimed to determine bone formation in clinically more relevant critical femoral bone defects in rats after grafting with open porous $\beta$-TCP and HA ceramics, which were previously shown to significantly differ in their osteoinductive potential. ${ }^{16}$ Our current findings indicated that at the selected implantation site, the amount of bone formed in both ceramics was limited and not sufficient to bridge the defect within the implantation period of 8 weeks. Nevertheless, the $\beta$-TCP ceramic which had previously demonstrated a superior osteoinductivity as compared to the HA upon heterotopic implantation, also resulted in a comparatively greater amount of bone within the critical-sized bone defect used here. Further, based on the histological analysis of the inflammatory response elicited postimplantation, we observed that inflammation in both $\beta$-TCP and HA subsides between 12 days and 6 weeks while bone formation was initiated between 12 days and 4 weeks. Considering that no obvious differences between the two ceramics were observed regarding the timing and the extent of inflammation, neither one of these parameters could be related to the difference in the amount of bone formed.

Comparison between ceramics with known differences osteoinductivity in orthotopic defects is limited. Gosain et al. $^{17,18}$ demonstrated that HA-TCP cement with higher osteoinductive potential showed superior performance in a critical-sized calvarial sheep model as compared to the non osteoinductive pure HA cement after 1 year. In another study, two BCP ceramics, having similar chemical composition but significantly different microstructure were compared intramuscularly as well as in an iliac wing defect in goats after 3 months. ${ }^{22}$ The BCP ceramic with a greater surface area as a result of a higher microporosity was more osteoinductive at the heterotopic location and performed significantly better in the iliac wing defect than the non osteoinductive BCP. Superiority in osteoinductive potential of the BCP ceramic was also reflected in the larger amount of bone formed after 3 months in a decorticated transverse process model in goats that represents the first stages of spinal fusion. ${ }^{23}$

Bone formation observed after implantation of $\beta$-TCP and HA ceramics in rats femurs was rather limited compared to bone formation observed after implantation of these ceramics in dogs and goats, ${ }^{16}$ even though bone healing capacity is generally believed to be less in larger animals. ${ }^{24}$ Compared to these studies, we used a relatively short implantation period, but this is not believed to be a likely explanation for the low amounts of bone observed as $\mathrm{we}^{19}$ and others ${ }^{25,26}$ have shown substantial bone healing responses in femoral bone defects within 8 weeks. However, bone healing capacity is also strongly affected by local biological and biomechanical factors at the site of implantation. Implantation in a segmental bone defect, a weight-bearing orthotopic site, will greatly increase the influence of biomechanical factors on bone healing, whereas biomechanical factors play only a minimal role in ectopic (intramuscular or paraspinal) implantation sites. Both the loading over the defect, as well as the fixation conditions used, may have diminished bone formation by hampering endochondral ossification. However, these conditions mimic clinical relevant bone defects that require bone grafting, as most bone defects result from fractures of long bones. So this weightbearing orthotopic bone defect might be more suitable for making claims toward the use of these ceramics in specific clinical applications, whereas the ectopic models provide insight in osteoinductive capacity and might help to unravel underlying mechanisms.

The greater amount of bone formation upon implantation of $\beta$-TCP compared to HA, cannot be solemnly attributed to a higher osteoinductive potential of $\beta$-TCP. For example, it cannot be excluded that higher microporosity resulting in a twelve times greater surface area positively affected osteoconductive potential of $\beta$-TCP. In fact, our finding of a significantly higher percentage of bone in the available pore area in the total region of interest without significant difference within the central portion of the implant, points to the fact that the difference in bone formation between the two CaP ceramics was in the peripheral area. As osteoconduction per definition proceeds from the host bone bed, bone in the periphery of the implant is likely the result of osteoconduction. In the central area of the implant, the material is not in direct contact with the osteogenic cells present in the host bone bed. However, without studies that determine the origin of new bone formation, it is difficult to prove that the bone formed within the central pores of the implant is due to direct differentiation of the inducible osteoprogenitor cells present in the bone marrow or the surrounding muscle, thus osteoinduction.

Although our results confirm bone healing capacity is greater with $\beta$-TCP as compared to HA, dynamics of inflammation were equal for the two ceramics. $\beta$-TCP and HA resulted in a inflammatory reaction during the first 2 weeks, as is generally seen within bone healing, ${ }^{27}$ which subsides by 6 weeks. Because we compared two ceramics with different physicochemical properties (Table I), their behavior upon a inflammatory environment may be different ( $\mathrm{pH}$ changes and calcium and phosphate ion release). However, this became not apparent in the dynamics of bone formation, because fluorochrome analysis revealed that bone formation had started at around 4 weeks in both $\beta$-TCP and HA.

\section{REFERENCES}

1. Petite $H$, Viateau V, Bensaid W, Meunier A, de Pollak C, Bourguignon M, Oudina K, Sedel L, Guillemin G. Tissue-engineered bone regeneration. Nat Biotechnol 2000;18(9):959-963.

2. Damien CJ, Parsons JR. Bone graft and bone graft substitutes: A review of current technology and applications. J Appl Biomater $1991 ; 2(3): 187-208$. 
3. Giannoudis PV, Dinopoulos H, Tsiridis E. Bone substitutes: An update. Injury 2005;36(suppl 3):S20-S27.

4. Dorozhkin SV. Bioceramics of calcium orthophosphates. Biomaterials 2010;31(7):1465-1485

5. Van der Stok J, Van Lieshout EMM, El-Massoudi Y, Van Kralingen $\mathrm{GH}$, Patka P. Bone substitutes in the Netherlands-A systematic literature review. Acta Biomater 2011;7(2):739-750.

6. Klein C, de Groot K, Chen W, Li Y, Zhang X. Osseous substance formation induced in porous calcium phosphate ceramics in soft tissues. Biomaterials 1994;15(1):31-34.

7. Yamasaki H, Sakai H. Osteogenic response to porous hydroxyapatite ceramics under the skin of dogs. Biomaterials 1992;13(5):308 312.

8. Yang Z, Yuan H, Tong W, Zou P, Chen W, Zhang X. Osteogenesis in extraskeletally implanted porous calcium phosphate ceramics: Variability among different kinds of animals. Biomaterials 1996; 17(22):2131-2137.

9. Yang ZJ, Yuan H, Zou P, Tong W, Qu S, Zhang XD. Osteogenic responses to extraskeletally implanted synthetic porous calcium phosphate ceramics: An early stage histomorphological study in dogs. J Mater Sci Mater Med 1997;8(11):697-701.

10. Barradas AM, Yuan H, van Blitterswijk CA, Habibovic P. Osteoinductive biomaterials: Current knowledge of properties, experimental models and biological mechanisms. Eur Cell Mater 2011; 21:407-429; discussion 429.

11. Urist MR. Bone: Formation by autoinduction. Science 1965; 150(3698):893-899.

12. Fellah BH, Delorme B, Sohier J, Magne D, Hardouin P, Layrolle P. Macrophage and osteoblast responses to biphasic calcium phosphate microparticles. J Biomed Mater Res A 2010;93(4):1588-1595.

13. Lin K, Yuan W, Wang L, Lu J, Chen L, Wang Z, Chang J. Evaluation of host inflammatory responses of beta-tricalcium phosphate bioceramics caused by calcium pyrophosphate impurity using a subcutaneous model. J Biomed Mater Res B: Appl Biomater 2011, 99(2):350-358

14. Morel O, Morel N, Jesel L, Freyssinet JM, Toti F. Microparticles: A critical component in the nexus between inflammation, immunity, and thrombosis. Semin Immunopathol 2011;33(5):469-486.

15. Friedenstein AY. Induction of bone tissue by transitional epithelium. Clin Orthop Relat Res 1968;59:21-37.

16. Yuan $H$, Fernandes $H$, Habibovic $P$, de Boer J, Barradas AM, de Ruiter A, Walsh WR, van Blitterswijk CA, de Bruijn JD. Osteoinductive ceramics as a synthetic alternative to autologous bone grafting. Proc Natl Acad Sci USA 2010;107(31):13614-13619.

17. Gosain AK, Song L, Riordan P, Amarante MT, Nagy PG, Wilson CR, Toth JM, Ricci JL. A 1-year study of osteoinduction in hydroxyapatite-derived biomaterials in an adult sheep model: Part I. Plast Reconstr Surg 2002;109(2):619-630.

18. Gosain AK, Riordan PA, Song L, Amarante MT, Kalantarian B, Nagy PG, Wilson CR, Toth JM, Mclntyre BL. A 1-year study of osteoinduction in hydroxyapatite-derived biomaterials in an adult sheep model: Part II. Bioengineering implants to optimize bone replacement in reconstruction of cranial defects. Plast Reconstr Surg 2004;114(5):1155-1163; discussion 1164-1165.

19. Van der Stok J, Van der Jagt OP, Amin Yavari S, De Haas MFP, Waarsing JH, Jahr H, Van Lieshout EMM, Patka P, Verhaar JAN, Zadpoor AA, Weinans $H$. Selective laser melting-produced porous titanium scaffolds regenerate bone in critical size cortical bone defects. J Orthop Res 2013;31(5):792-799.

20. Geuze RE, Everts PA, Kruyt MC, Verbout AJ, Alblas J, Dhert WJ. Orthotopic location has limited benefit from allogeneic or autologous multipotent stromal cells seeded on ceramic scaffolds. Tissue Eng Part A 2009;15(11):3231-3239.

21. Yuan H, Van Den Doel M, Li S, Van Blitterswijk CA, De Groot K, De Bruijn JD. A comparison of the osteoinductive potential of two calcium phosphate ceramics implanted intramuscularly in goats. J Mater Sci Mater Med 2002;13(12):1271-1275.

22. Habibovic $P$, Yuan $H$, van den Doel $M$, Sees TM, van Blitterswijk CA, de Groot K. Relevance of osteoinductive biomaterials in critical-sized orthotopic defect. J Orthop Res 2006;24(5):867-876.

23. Habibovic P, Kruyt MC, Juhl MV, Clyens S, Martinetti R, Dolcini L, Theilgaard N, van Blitterswijk CA. Comparative in vivo study of six hydroxyapatite-based bone graft substitutes. J Orthop Res 2008;26(10):1363-1370.

24. Zoetis T, Tassinari MS, Bagi C, Walthall K, Hurtt ME. Species comparison of postnatal bone growth and development. Birth Defects Res B: Dev Reprod Toxicol 2003;68(2):86-110.

25. Histing T, Garcia P, Holstein JH, Klein M, Matthys R, Nuetzi R, Steck R, Laschke MW, Wehner T, Bindl R, Recknagel S, Stuermer EK, Vollmar B, Wildemann B, Lienau J, Willie B, Peters A, Ignatius A, Pohlemann T, Claes L, Menger MD. Small animal bone healing models: Standards, tips, and pitfalls results of a consensus meeting. Bone 2011;49(4):591-599.

26. Angle SR, Sena K, Sumner DR, Virkus WW, Virdi AS. Healing of rat femoral segmental defect with bone morphogenetic protein-2: A dose response study. J Musculoskelet Neuronal Interact 2012; 12(1):28-37.

27. Claes $L$, Recknagel $S$, Ignatius $A$. Fracture healing under healthy and inflammatory conditions. Nat Rev Rheumatol 2012;8(3):133143. 